\title{
Apnea in Term and Late Preterm Neonates Born to Coronavirus Infected Mothers
}

Jaimin Patel, MD, MSMI. Jagdish Desai, MD, MPH, Renjithkumar Kalikkot Thekkeveedu, MD, Tasha N. Coleman, MD, Nilesh Dankhara, MBBS, Alisia C. Hankins, DNP, NNP-BC Mobolaji E. Famuyide, MD

\begin{abstract}
:
We report three otherwise healthy neonates born to Coronavirus Disease-19 (COVID-19) positive mothers who developed apnea during birth admission but tested negative for COVID-19. We postulate that the apnea may be due to transplacental transmission of inflammatory cytokines. We strongly advise against early discharge in babies born to mothers with active COVID-19 infection.
\end{abstract}

\section{Established Facts and Novel Insights:}

Established Facts:

1. Limited data is available regarding the clinical presentation of infants born to COVID-19 positive mothers.

2. There is a paucity of data on false-negative rates of the COVID-19 RT-RNA PCR test in neonates.

3. There is no proven vertical transmission of COVID-19 infection to newborns. Inconsistent evidence exists regarding the Coronavirus's presence in amniotic fluid, placenta, umbilical cord blood, and breast milk samples.

Novel Insights:

1. Infants born to COVID-19 positive mothers may present with apnea despite testing negative for COVID-19. Close monitoring is needed.

2. There could be a cytokine storm released during maternal COVID-19 illness responsible for apnea, in the absence of viral transmission. Further studies are required to prove this hypothesis.

Keywords: Apnea; Neonate; COVID-19; Coronavirus; transmission; perinatal; cytokines

Abbreviations: $\mathrm{BE}=$ Base Excess, $\mathrm{WBC}=$ White blood cell, $\mathrm{CRP}=\mathrm{C}$ reactive protein, $\mathrm{C}$-section $=$ Cesarean section, $\mathrm{SVD}=$ Spontaneous vaginal delivery, $\mathrm{CT}=$ computed tomography, $\mathrm{DOL}=$ Day of life, NICU=Neonatal intensive care unit.

Introduction:

COVID-19 syndrome in pregnancy is often reported as mild to moderate in severity. $(1,2)$ The clinical presentation of COVID-19 syndrome in pregnancy is similar to that seen in non-pregnant adults. Coronavirus infection in pregnancy is associated with hospitalization and increased risk for intensive care unit admission and receipt of mechanical ventilation(3). Questions surrounding perinatal care of mother and baby, such as clinical features in neonates, mode of transmission, particularly vertical transmission, delivery room care and isolation and timing of removal from isolation, and transmission through breast milk are still under scrutiny, and answers are evolving as more evidence is emerging. (4)

Variable clinical presentation of babies with a positive viral test for the COVID-19 infection is reported in the literature. (5-7) Most neonates born to mothers with COVID-19 infection are asymptomatic or only have mild symptoms. Lu et al. have reported fever, cough, and fatigue as the most common symptoms in neonates and children. (5) Nasal congestion, tachypnea, and reduced feeding have also been reported. (6) Respiratory symptoms may range from mild hypoxemia requiring oxygen therapy to respiratory failure requiring ventilatory support in neonates. Some patients may develop pneumonia, acute respiratory syndrome, and pneumothorax. (6)

"In our case series, we report a series of term and a late preterm neonate born to COVID-19 infected mothers who presented with apnea, bradycardia, and desaturation episodes during birth hospital admission."

Apnea is common in preterm infants; however, it is a rare clinical event in full-term infants, occurring at a rate of one per 1000 . (8) Although the pathophysiology is not completely understood, intrauterine or perinatal inflammation may be an important factor. Pro-inflammatory cytokines, such as interleukin-1b (IL-1b), have been reported as triggers for central apnea and problems with respiratory control. (9) Common considerations when a full-term neonate presents with apnea in the delivery room or neonatal period include perinatal injury from hypoxia and ischemia, inflammation secondary to pneumonia or early-onset sepsis, central nervous system abnormalities including trauma, intracranial hemorrhage or seizures, and intrapartum maternal drug (e.g., narcotic or magnesium or general anesthesia) administration. (9)

In our case series, we report a series of term and a late preterm neonate born to COVID-19 infected mothers who presented with apnea, bradycardia, and desaturation episodes during birth hospital admission.

\section{Case Report/Case Presentation}

We describe the clinical presentation of three neonates born to

NEONATOLOGY TODAY is interested in publishing manuscripts from Neonatologists, Fellows, NNPs and those involved in caring for neonates on case studies, research results, hospital news, meeting announcements, and other pertinent topics.

Please submit your manuscript to: LomaLindaPublishingCompany@gmail.com 
COVID-19 positive mothers who became symptomatic during observation in-hospital after birth. The management of infants born to COVID-19 positive mothers in our institution is based on guidance from the American Academy of Pediatrics (AAP). Twentytwo mothers were admitted with COVID-19 positive status at the time of delivery from March 2020 to June 2020. Three (13.6\%) of the 22 infants born to these mothers developed apnea of undetermined etiology during admission. Written informed consent was obtained from guardians regarding sharing information for scientific or teaching purposes, including research.

"Twenty-two mothers were admitted with COVID-19 positive status at the time of delivery from March 2020 to June 2020. Three (13.6\%) of the 22 infants born to these mothers developed apnea of undetermined etiology during admission."
Neonate 1 was born to a 22-year-old Gravida 3, Term 2, Preterm 1, Abortion 0, Living 3 (G3P2103) mother at 40 weeks of gestation via C-Section and presented with apnea at 26 hours of age. Neonate 2 was born to a 17-year-old G2P0010 mother at 35 weeks 6 days of gestation via C-Section and presented with apnea at 19 hours of age. Neonate 3 was born to a 28-year-old G2P2002 mother at 40 weeks of gestation via vaginal delivery and presented with apnea at 65 hours of age. All babies were discharged home spontaneously breathing in Room Air (RA). Table 1 provides a comprehensive description of the three dyads.

\section{"Even in the absence of vertical transmission of the virus, the maternal illness may have detrimental effects on the fetus/neonate."}

\section{Discussion/Conclusion:}

Clinical features in neonates born to mothers with COVID-19 infection vary. We present three neonates born at term/late preterm gestational age, who tested negative for Coronavirus via real-time polymerase chain reaction (RT-PCR), yet presented with apnea-

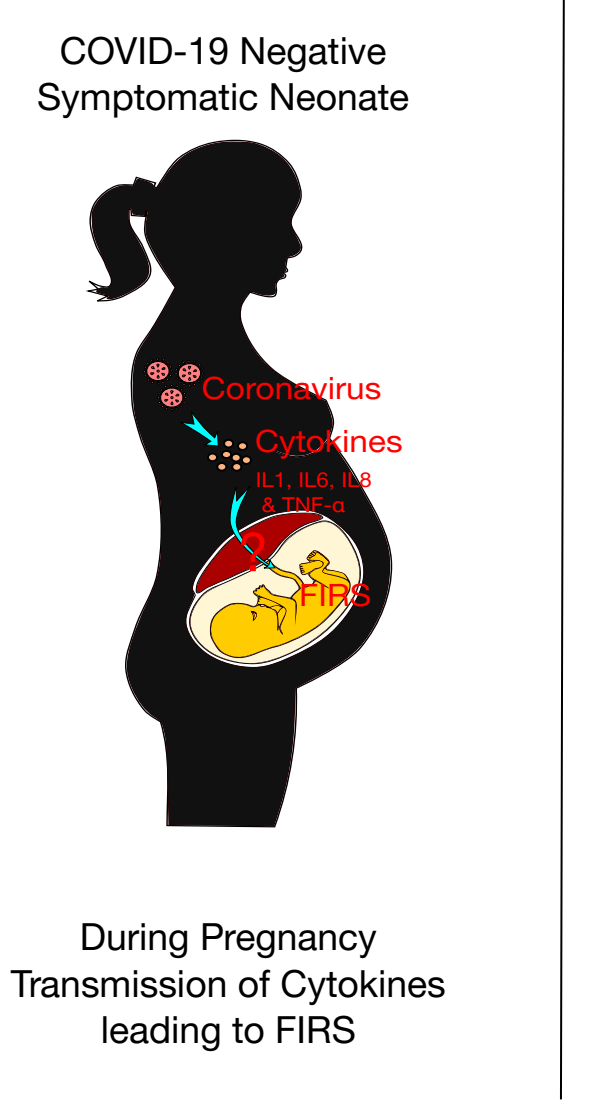

\section{COVID-19 Positive \\ Symptomatic Neonate}

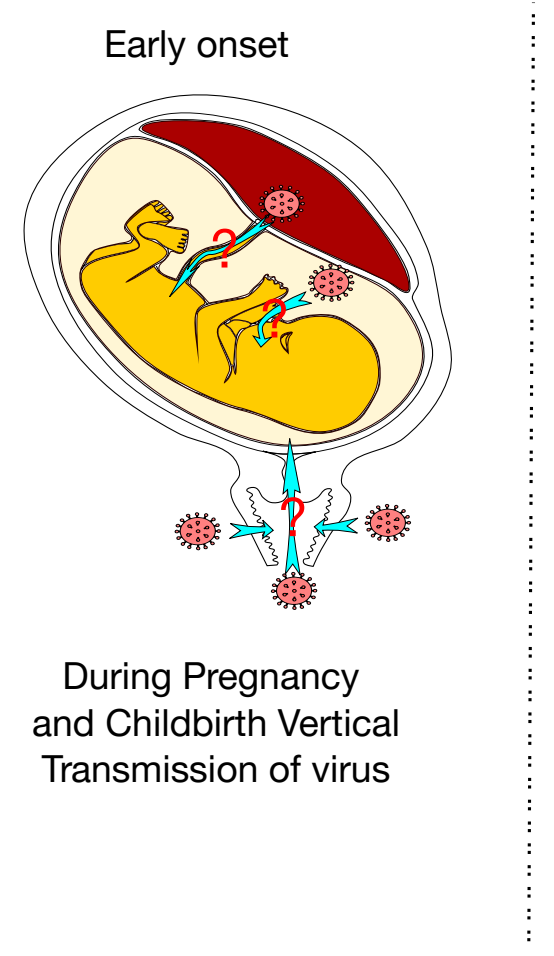

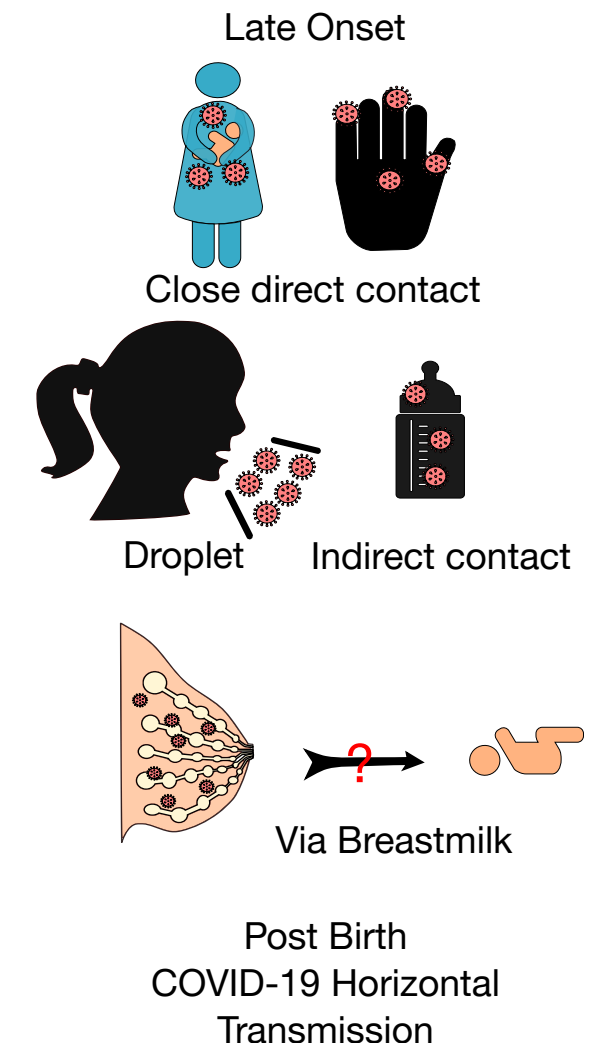

Figure 1: Symptomatic neonates born to mother with COVID-19-possible pathophysiology and transmission modes. 
Table 1: Maternal Characteristics

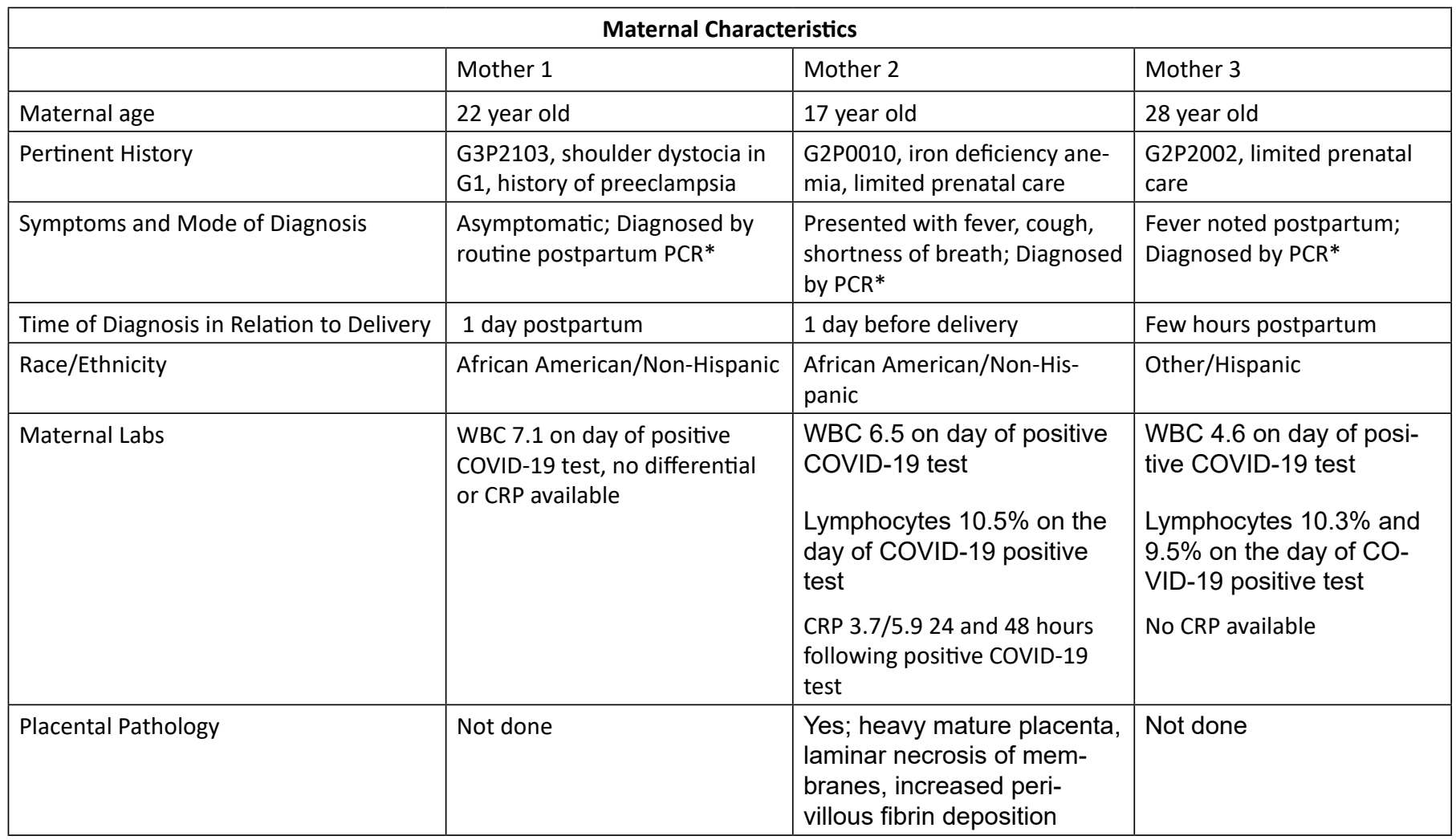

Table 1: Clinical presentation of three neonates born to COVID-19 positive mothers. Footnote: *PCR=SARS-CoV-2 RNA RT-PCR

**Infant COVID-19 testing all by nasopharyngeal SARS-CoV-2 RNA RT-PCR

bradycardia-desaturation episodes, which are uncommon in this gestational age group. We hypothesize that this is due to the transplacental transfer of inflammatory cytokines from the mother to the baby.

The clinical presentation of symptomatic infants born to COVID-19 positive mothers can be broadly classified into three possible theoretical scenarios: (i) neonates who test negative for COVID-19 but are symptomatic possibly due to fetal inflammatory response syndrome from maternal inflammation and transplacental transfer of cytokines (ii) neonates who test positive immediately after birth (early-onset infection) due to possible verticle transmission (iii) neonates who test positive after discharged home and thus presented late (late-onset infection), due to possible horizontal transmission from infected caregivers (Figure 1).

The American Academy of Pediatrics Section on Neonatal-Perinatal Medicine (AAP SONPM) National Registry of Perinatal COVID-19 Infection (NPC-19) describes the majority of the reported deliveries as occurring vaginally $(60 \%)$ at term or late preterm gestations with a median GA of 39 weeks (range of 15-45 weeks) to White (35\%)/Non-Hispanic (50.3\%) mothers. (10) At our center, deliveries for COVID-19 positive mothers have occurred mostly vaginally $(58 \%)$ at term or late preterm gestations with a median GA of 39 weeks (range of 26-41 weeks) to predominantly Hispanic mothers (55\%). Common symptoms reported in mothers were fever, cough, malaise/weakness, myalgia, dyspnea, sore throat, diarrhea, and chest pain. (11-15) Laboratory features commonly reported include lymphocytopenia and elevated inflammatory markers such as $\operatorname{CRP}(16-18)$, abnormal LFT(19), and imaging findings consistent with pneumonia. $(17,19,20)$ Severely affected patients may develop abnormalities of liver enzymes, acute renal failure, and coagulopathy-disseminated intravascular coagulation (DIC). $(21,22)$

The consequences of COVID-19 infection early in pregnancy are largely unknown at this time. (23) Transmission of COVID-19 disease to the baby can occur intrauterine or during the peripartum and/or postpartum period. However, the chances of intrauterine infection remain low. $(20,23,24)$ Placental changes like fibrin deposition and malperfusion have been reported(25), and there is evidence of Coronavirus being present and invading syncytiotrophoblast in the human placenta; $(26,27)$ although, the neonate in the same pregnancy tested negative for COVID-19. Multiple case reports suggest that viral tests for COVID-19 are negative in amniotic fluid and umbilical cord. $(17,23,28)$ Several authors have also suggested that vertical transmission in utero is rare or did not occur $(7,11,29,30)$; however, in some cases, vertical transmission is suggested. (31) Dong et al. reported a case where a neonate born to a COVID-19 positive mother had elevated IgM antibodies at 2 hours. IgM antibodies are not transmitted to the fetus via the placenta, and hence its presence may suggest vertical transmission. (31) This infant also had elevated cytokines and AST, although repeated RT-PCR tests on nasopharyngeal swabs 
Table 2: Infant Characteristics

\begin{tabular}{|c|c|c|c|}
\hline \multicolumn{4}{|c|}{ Delivery Information } \\
\hline & Infant 1 & Infant 2 & Infant 3 \\
\hline Gender & Female & Female & Male \\
\hline Birthweight & 2920 grams & 2450 grams & 3070 grams \\
\hline Mode of delivery & C-Section & C-Section & SVD \\
\hline $\begin{array}{l}\text { APGARs (at } 1 \text { and } 5 \text { minutes respec- } \\
\text { tively) }\end{array}$ & $8 / 9$ & $8 / 9$ & $8 / 9$ \\
\hline $\begin{array}{l}\text { Cord Blood Gas } \\
\text { (pH/PCO2/PaO2/HCO3/BE) }\end{array}$ & $7.21 / 77 / 19 / 30.8 / 1$ & Not done & Not done \\
\hline Infant Signs and Symptoms & Apnea and desaturations & Apnea and desaturations & Apnea and emesis \\
\hline Highest Respiratory Support & $\begin{array}{l}2 \text { Liters high flow nasal can- } \\
\text { nula }\end{array}$ & $\begin{array}{l}\text { Continuous positive airway } \\
\text { pressure at } 5 \mathrm{~cm} \mathrm{H} 2 \mathrm{O}\end{array}$ & $\begin{array}{l}\text { Continuous positive } \\
\text { airway pressure at } 5 \mathrm{~cm} \\
\mathrm{H} 2 \mathrm{O}\end{array}$ \\
\hline Pertinent diagnostics & $\begin{array}{l}\text { Normal CT head } \\
\text { Labs unremarkable }\end{array}$ & $\begin{array}{l}\text { Normal chest } x \text {-ray and } \\
\text { head ultrasound } \\
\text { Labs unremarkable }\end{array}$ & $\begin{array}{l}\text { Normal chest x-ray and } \\
\text { head ultrasound } \\
\text { Labs unremarkable }\end{array}$ \\
\hline Timing of COVID-19 Testing** & DOL 1,2 , and 7 & DOL $1,2,6$, and 7 & DOL 1,2 , and 3 \\
\hline Testing Results & Negative & Negative & Negative \\
\hline
\end{tabular}

remained negative. Zamaniyan et al. have also reported vertical transmission(32) in a neonate born to a COVID-19 positive mother. The amniotic fluid was positive for COVID-19, and this neonate developed a fever at birth. Although the infant's first nasopharyngeal and throat PCR tests, which were done at delivery, were negative, the second test done 24 hours later was positive, as were the third and fourth PCR tests done a week later.

Even in the absence of vertical transmission of the virus, the maternal illness may have detrimental effects on the fetus/neonate. Zhao et al. described a clinical entity called fetal inflammatory response syndrome (FIRS) from maternal COVID-19 infection in the absence of placenta infection with the virus. (33) The mother's immune response to infection promotes the fetal inflammatory response characterized by high levels of inflammatory cytokines in the placenta, such as IL-1, IL-6, IL-8, and TNF- $\alpha$, even while negative for culture/PCR for microorganisms. These cytokines have been shown to affect the central nervous system and circulatory system and tend to cause abnormal fetal morphology in animal models, including ventricular expansion and bleeding. (34-37) Similar inflammatory responses from other infections have been suggested to lead to long term neurodevelopmental and psychological abnormalities. (38) Therefore, proactive management of the cytokine storm in mothers with COVID-19 infection could mitigate its negative impact on fetal development.

Most of the babies delivered in our institution at $\geq 35$ weeks GA were asymptomatic throughout hospitalization (87\%), a number comparable to data from the NPC-19 registry $(84 \%)(10)$. Common symptoms reported in neonates born to COVID-19 positive mothers are respiratory distress $(13-14 \% \%)(10,39)$, fever $(1-2 \%)(10$, $24,39)$, tachycardia (39), hypotonia, radiological findings of pneumonia (40), thrombocytopenia $(39,41)$, Iymphocytopenia $(40,41)$ (24), disseminated intravascular coagulation (DIC) $(39,41)$, refus-

NEONATOLOGY TODAY is interested in publishing manuscripts from Neonatologists, Fellows, NNPs and those involved in caring for neonates on case studies, research results, hospital news, meeting announcements, and other pertinent topics.

Please submit your manuscript to: LomaLindaPublishingCompany@gmail.com 
al of feeding and feeding intolerance (39), vomiting (39), gastric bleeding(39), necrotizing enterocolitis, jejunal perforations (41), abnormal liver functions $(39,40)$, refractory shock(39). Chen et al. also reported elevated myocardial enzymes in a baby.(20) All these babies tested negative for the virus with RT PCR. Hence, it is difficult to attribute these symptoms solely to the viral infection. Apnea has not been separately reported in either the AAP registry or any other case series. There is a possibility that it might have been included with other respiratory symptoms and hence true incidence apnea is unknown in late preterm born to COVID-19 positive mothers is unknown.

There is a wide variation in neonatal testing suggested. This varies from nasopharyngeal, oropharyngeal, and rectal swabs at 24 to $48 \mathrm{hrs}$ after birth (six swabs) on one end of the spectrum to no testing if asymptomatic on the other. (29) At our institution, we routinely test all neonates born to COVID-19 infected mothers 24 and 48 hours after birth. There is good data on the test's accuracy, but there is no data on the validity of the technique or timing of testing in neonates. Due to sample collection difficulty in neonates (strong gag reflex, small nasal passage, fear of going too far in the nasopharyngeal area) and possibly inadequate training, there is a high possibility of a high false-negative rate. The best time for sample collection after birth to detect vertical transmission remains controversial.(42) Early testing might be falsely negative due to a low viral load. All of the neonates in this series tested negative for SARS-CoV-2 at least three times; however, they were not tested for IgM and IgG for COVID-19. Apnea in these infants may also be associated with rhinovirus and other respiratory viruses, such as Respiratory Syncytial virus, metapneumovirus etc.; these were not tested in either mother or neonates as our focus was only on COVID-19 infection.

The NPC-19 Registry reports that $30 \%$ of infants born to a COVID-19 positive mother required some type of respiratory support at delivery. (10) The majority of the infants in this registry roomed in with the mother $(50 \%)$, while $29 \%$ were admitted to a NICU and $21 \%$ monitored in the nursery. Fifty-eight percent of these infants were placed on contact/droplet/airborne isolation in a negative pressure room. (10) At the time of this report, our center separated all infants born to a COVID-19 positive mother and monitored in a negative pressure isolation room until two COVID-19 RT PCR tests from nasopharyngeal swabs obtained at 24 hours and 48 hours were negative and the infant cleared by infectious disease specialists. However, there is significant variability across the country regarding the location of care (separation versus rooming-in with mother) for term/late preterm asymptomatic neonates. The median hospital stay for term neonates in our institution was four days (range 4-11 days), similar to the NPC-19 registry mean hospital stay of 4.88 days (range of 0-80 days).(10) These practices are in line with the AAP interim guidance, which discourages early discharge and recommends that newborn discharge should be based on each center's usual criteria. $(43,44)$

To date, apnea has not been reported in babies born to mothers with COVID-19 in term or late preterm infants. Apnea of prematurity is a commonly seen symptom in premature neonates, and apnea typically does not occur in full-term and near-term neonates. In our case series, we report apnea-bradycardia-desaturation episodes in near term /late preterm neonates born to mothers with COVID-19 infection. The AAP interim guidance discourages early discharge, which is traditionally defined as $<48 \mathrm{~h}$ following a vaginal birth and $<96 \mathrm{~h}$ following cesarean delivery. This guidance recommends that newborn discharge should be based on each center's usual criteria. (43) These neonates presented with apnea between 19-65 hours after birth, which falls within the time frame for in-hospital newborn monitoring in the majority of newborn practices across the United States, depending on the route of delivery.

Due to the variability in the presentation of clinical features related to the fetal response to maternal inflammation from COVID-19 infection, we recommend closer monitoring, even when rooming-in, following birth admission, and strongly caution against early discharge. Further studies are needed to confirm the hypothesis of maternal cytokine storm during maternal illness as the cause of apnea in the absence of viral transmission.

\section{"Apnea has not been separately reported in either the AAP registry or any other case series. There is a possibility that it might have been included with other respiratory symptoms and hence true incidence apnea is unknown in late preterm born to COVID-19 positive mothers is unknown."}

\section{References:}

1. Ferrazzi E, Frigerio L, Savasi V, Vergani P, Prefumo F, Barresi $S$, et al. Vaginal delivery in SARS-CoV-2-infected pregnant women in Northern Italy: a retrospective analysis. Bjog. 2020. Epub 2020/04/28. doi: 10.1111/1471-0528.16278. PubMed PMID: 32339382; PubMed Central PMCID: PMCPMC7267664.

2. Chen L, Li Q, Zheng D, Jiang $H$, Wei Y, Zou L, et al. Clinical Characteristics of Pregnant Women with Covid-19 in Wuhan, China. N Engl J Med. 2020. Epub 2020/04/18. doi: 10.1056/ NEJMc2009226. PubMed PMID: 32302077; PubMed Central PMCID: PMCPMC7182016.

3. Ellington S, Strid P, Tong VT, Woodworth K, Galang RR, Zambrano LD, et al. Characteristics of Women of Reproductive Age with Laboratory-Confirmed SARS-CoV-2 Infection by Pregnancy Status - United States, January 22-June 7, 2020. MMWR Morb Mortal Wkly Rep. 2020;69(25):769-75. Epub 2020/06/26. doi: 10.15585/mmwr.mm6925a1. PubMed PMID: 32584795.

4. Mimouni F, Lakshminrusimha S, Pearlman SA, Raju T, Gallagher PG, Mendlovic J. Perinatal aspects on the covid-19 pandemic: a practical resource for perinatal-neonatal specialists. Journal of Perinatology. 2020;40(5):820-6. doi: 10.1038/s41372-020-0665-6.

5. Lu Q, Shi Y. Coronavirus disease (COVID $\square 19)$ and neonate: What neonatologist need to know. Journal of Medical Virology. 2020;92(6):564-7. doi: 10.1002/jmv.25740.

6. Coronado Munoz A, Nawaratne U, McMann D, Ellsworth M, Meliones J, Boukas K. Late-Onset Neonatal Sepsis in a Patient with Covid-19. New England Journal of Medicine. 2020;382(19):e49. doi: 10.1056/nejmc2010614. 
7. Piersigilli F, Carkeek K, Hocq C, Van Grambezen B, Hubinont $C$, Chatzis O, et al. COVID-19 in a 26-week preterm neonate. The Lancet Child \& Adolescent Health. 2020;4(6):4768. doi: 10.1016/s2352-4642(20)30140-1.

8. Levin JC, Jang J, Rhein LM. Apnea in the Otherwise Healthy, Term Newborn: National Prevalence and Utilization during the Birth Hospitalization. J Pediatr. 2017;181:67-73 e1. Epub 2016/11/21. doi: 10.1016/j.jpeds.2016.10.029. PubMed PMID: 27865430.

9. Patrinos ME, Martin RJ. Apnea in the term infant. Seminars in Fetal and Neonatal Medicine. 2017;22(4):240-4. doi: 10.1016/j.siny.2017.04.003.

10. National Registry for Surveillance and Epidemiology of Perinatal COVID-19 Infection [Internet]. AAP Section of SONPM COVID-19 Resources. 2020 [cited 07/24/2020]. Available from: $\quad$ https://collaborate.aap.org/SONPM/Pages/NationalPerinatal-COVID19-Registry.aspx.

11. Chen H, Guo J, Wang C, Luo F, Yu X, Zhang $W$, et al. Clinical characteristics and intrauterine vertical transmission potential of COVID-19 infection in nine pregnant women: a retrospective review of medical records. The Lancet. 2020;395(10226):809-15. doi: 10.1016/s01406736(20)30360-3.

12. Breslin N, Baptiste C, Gyamfi-Bannerman C, Miller R, Martinez R, Bernstein K, et al. Coronavirus disease 2019 infection among asymptomatic and symptomatic pregnant women: two weeks of confirmed presentations to an affiliated pair of New York City hospitals. American Journal of Obstetrics \& Gynecology MFM. 2020;2(2):100118. doi: 10.1016/j. ajogmf.2020.100118.

13. Liu D, Li L, Wu X, Zheng D, Wang J, Yang L, et al. Pregnancy and Perinatal Outcomes of Women With Coronavirus Disease (COVID-19) Pneumonia: A Preliminary Analysis. American Journal of Roentgenology. 2020:1-6. doi: 10.2214/ AJR.20.23072.

14. Schwartz DA. An Analysis of 38 Pregnant Women with COVID-19, Their Newborn Infants, and Maternal-Fetal Transmission of SARS-CoV-2: Maternal Coronavirus Infections and Pregnancy Outcomes. Archives of Pathology \& Laboratory Medicine. 2020. doi: 10.5858/arpa.2020-0901-SA.

15. Zaigham M, Andersson O. Maternal and perinatal outcomes with COVID-19: A systematic review of 108 pregnancies. Acta Obstetricia et Gynecologica Scandinavica. 2020. doi: 10.1111/aogs.13867.

16. Zaigham M, Andersson O. Maternal and perinatal outcomes with COVID-19: A systematic review of 108 pregnancies. Acta Obstet Gynecol Scand. 2020. Epub 2020/04/08. doi: 10.1111/aogs.13867. PubMed PMID: 32259279; PubMed Central PMCID: PMCPMC7262097.

17. Schwartz DA. An Analysis of 38 Pregnant Women with COVID-19, Their Newborn Infants, and Maternal-Fetal Transmission of SARS-CoV-2: Maternal Coronavirus Infections and Pregnancy Outcomes. Arch Pathol Lab Med. 2020. Epub 2020/03/18. doi: 10.5858/arpa.2020-0901-SA. PubMed PMID: 32180426.

18. Liu D, Li L, Wu X, Zheng D, Wang J, Yang L, et al. Pregnancy and Perinatal Outcomes of Women With Coronavirus Disease (COVID-19) Pneumonia: A Preliminary Analysis. AJR Am J Roentgenol. 2020:1-6. Epub 2020/03/19. doi: 10.2214/ ajr.20.23072. PubMed PMID: 32186894.

19. Yu N, Li W, Kang Q, Xiong Z, Wang S, Lin X, et al. Clini- cal features and obstetric and neonatal outcomes of pregnant patients with COVID-19 in Wuhan, China: a retrospective, single-centre, descriptive study. Lancet Infect Dis. 2020;20(5):559-64. Epub 2020/03/30. doi: 10.1016/s14733099(20)30176-6. PubMed PMID: 32220284; PubMed Central PMCID: PMCPMC7158904.

20. Chen H, Guo J, Wang C, Luo F, Yu X, Zhang W, et al. Clinical characteristics and intrauterine vertical transmission potential of COVID-19 infection in nine pregnant women: a retrospective review of medical records. Lancet. 2020;395(10226):809-15. Epub 2020/03/11. doi: 10.1016/ s0140-6736(20)30360-3. PubMed PMID: 32151335; PubMed Central PMCID: PMCPMC7159281.

21. Zhang $Y$, Xiao $M$, Zhang $S$, Xia $P$, Cao $W$, Jiang $W$, et al. Coagulopathy and Antiphospholipid Antibodies in $\mathrm{Pa}$ tients with Covid-19. New England Journal of Medicine. 2020;382(17):e38. doi: 10.1056/nejmc2007575.

22. Ng WF, Wong SF, Lam A, Mak YF, Yao H, Lee KC, et al. The placentas of patients with severe acute respiratory syndrome: a pathophysiological evaluation. Pathology. 2006;38(3):210-8. doi: 10.1080/00313020600696280.

23. Mimouni F, Lakshminrusimha S, Pearlman SA, Raju T, Gallagher PG, Mendlovic J. Perinatal aspects on the covid-19 pandemic: a practical resource for perinatal-neonatal specialists. J Perinatol. 2020;40(5):820-6. Epub 2020/04/12. doi: 10.1038/s41372-020-0665-6. PubMed PMID: 32277162; PubMed Central PMCID: PMCPMC7147357.

24. Fan $C$, Lei D, Fang C, Li C, Wang M, Liu Y, et al. Perinatal Transmission of COVID-19 Associated SARS-CoV-2: Should We Worry? Clin Infect Dis. 2020. Epub 2020/03/18. doi: 10.1093/cid/ciaa226. PubMed PMID: 32182347; PubMed Central PMCID: PMCPMC7184438.

25. Baergen RN, Heller DS. Placental Pathology in Covid-19 Positive Mothers: Preliminary Findings. Pediatr Dev Pathol. 2020;23(3):177-80. Epub 2020/05/14. doi: 10.1177/1093526620925569. PubMed PMID: 32397896.

26. Hillary Hosier SF, Raffaella Morotti, Uma Deshmukh, Alice Lu-Culligan, Katherine Campbell, Yuki Yasumoto, Chantal Vogels, Arnau Casanovas-Massana, Pavithra Vijayakumar, Bertie Geng, Camila Odio, John Fournier, Anderson Brito, Joseph Fauver, Feimei Liu, Tara Alpert, Reshef Tal, Klara Szigeti-Buck, Sudhir Perincheri, Christopher Larsen, Aileen Gariepy, Gabriela Aguilar, Kristen Fardelmann, Malini Harigopal, Hugh Taylor, Christian Pettker, Anne Wyllie, Charles Dela Cruz, Aaron Ring, Nathan Grubaugh, Albert Ko, Tamas Horvath, Akiko Iwasaki, Uma Reddy, Heather Lipkind. SARS-CoV-2 Infection of the Placenta. MedRxiv. doi: 10.1101/2020.04.30.20083907v3.

27. Algarroba GN, Rekawek P, Vahanian SA, Khullar P, Palaia T, Peltier MR, et al. Visualization of SARS-CoV-2 virus invading the human placenta using electron microscopy. American Journal of Obstetrics and Gynecology. 2020. doi: 10.1016/j. ajog.2020.05.023.

28. Chen $Y$, Peng $H$, Wang $L$, Zhao $Y$, Zeng $L$, Gao $H$, et al. Infants Born to Mothers With a New Coronavirus (COVID-19). Front Pediatr. 2020;8:104. Epub 2020/04/09. doi: 10.3389/ fped.2020.00104. PubMed PMID: 32266184; PubMed Central PMCID: PMCPMC7098456.

29. Chandrasekharan $P$, Vento $M$, Trevisanuto $D$, Partridge $E$, Underwood MA, Wiedeman J, et al. Neonatal Resuscitation and Postresuscitation Care of Infants Born to Mothers with 
Suspected or Confirmed SARS-CoV-2 Infection. American Journal of Perinatology. 2020. doi: 10.1055/s-0040-1709688.

30. Shek CC, Ng PC, Fung GPG, Cheng FWT, Chan PKS, Peiris MJS, et al. Infants Born to Mothers With Severe Acute Respiratory Syndrome. PEDIATRICS. 2003;112(4):e254-e. doi: 10.1542/peds.112.4.e254.

31. Dong L, Tian J, He S, Zhu C, Wang J, Liu C, et al. Possible Vertical Transmission of SARS-CoV-2 From an Infected Mother to Her Newborn. JAMA. 2020. doi: 10.1001/ jama.2020.4621.

32. Zamaniyan M, Ebadi A, Aghajanpoor Mir S, Rahmani Z, Haghshenas $M$, Azizi S. Preterm delivery in pregnant woman with critical COVID-19 pneumonia and vertical transmission. Prenatal Diagnosis. 2020. doi: 10.1002/pd.5713.

33. Zhao X, Jiang Y, Zhao Y, Xi H, Liu C, Qu F, et al. Analysis of the susceptibility to COVID-19 in pregnancy and recommendations on potential drug screening. Eur J Clin Microbiol Infect Dis. 2020;39(7):1209-20. Epub 2020/04/25. doi: 10.1007/s10096-020-03897-6. PubMed PMID: 32328850; PubMed Central PMCID: PMCPMC7178925.

34. Davies JK, Shikes RH, Sze C-I, Leslie KK, McDuffie RS, Romero $R$, et al. Histologic inflammation in the maternal and fetal compartments in a rabbit model of acute intraamniotic infection. 2000;183(5):1088-93. doi: 10.1067/ mob.2000.108888.

35. Madsen-Bouterse SA, Romero R, Tarca AL, Kusanovic JP, Espinoza J, Kim CJ, et al. ORIGINAL ARTICLE: The Transcriptome of the Fetal Inflammatory Response Syndrome. American Journal of Reproductive Immunology. 2009;63(1):73-92. doi: 10.1111/j.1600-0897.2009.00791.x.

36. Salaun B, Romero $P$, Lebecque S. Toll-like receptors' twoedged sword: when immunity meets apoptosis. European Journal of Immunology. 2007;37(12):3311-8. doi: 10.1002/ eji.200737744.

37. Deverman BE, Patterson PH. Cytokines and CNS Development. Neuron. 2009;64(1):61-78. doi: 10.1016/j.neuron.2009.09.002.

38. Ratnayake U, Quinn T, Walker DW, Dickinson H. Cytokines and the neurodevelopmental basis of mental illness. Front Neurosci. 2013;7:180. Epub 2013/10/23. doi: 10.3389/ fnins. 2013.00180. PubMed PMID: 24146637; PubMed Central PMCID: PMCPMC3797953.

39. Zhu H, Wang L, Fang C, Peng S, Zhang L, Chang G, et al. Clinical analysis of 10 neonates born to mothers with 2019nCoV pneumonia. Transl Pediatr. 2020;9(1):51-60. Epub 2020/03/11. doi: 10.21037/tp.2020.02.06. PubMed PMID: 32154135; PubMed Central PMCID: PMCPMC7036645.

40. Wang S, Guo L, Chen L, Liu W, Cao Y, Zhang J, et al. A case report of neonatal COVID-19 infection in China. Clin Infect Dis. 2020. Epub 2020/03/13. doi: 10.1093/cid/ciaa225. PubMed PMID: 32161941; PubMed Central PMCID: PMCPMC7108144.

41. Li AM, Ng PC. Severe acute respiratory syndrome (SARS) in neonates and children. Arch Dis Child Fetal Neonatal Ed. 2005;90(6):F461-5. Epub 2005/10/26. doi: 10.1136/ adc. 2005.075309. PubMed PMID: 16244207; PubMed Central PMCID: PMCPMC1721969.

42. CDC. Evaluation and Management Considerations for Neonates At Risk for COVID-192020 7/15/2020. Available from: https://www.cdc.gov/coronavirus/2019-ncov/hcp/caring-fornewborns.html.
43. Benitz WE. Hospital Stay for Healthy Term Newborn Infants. PEDIATRICS. 2015;135(5):948-53. doi: 10.1542/peds.20150699.

44. Wyckoff AS. AAP updates guidance on newborns whose mothers have suspected or confirmed COVID-19. AAP News. 2020.

Prior Publication: None

Funding: None.

Statements: Acknowledgment: We thank all the healthcare workers who took care of these patients at the University of Mississippi Medical Center, Jackson, MS

Statement of Ethics: According to the Institutional Review Board at the University of Mississippi Medical center, this study does not require IRB approval. Written informed consent was obtained from the guardian regarding use or disclose or share of information for scientific or teaching purposes including research.

\section{Funding Sources}

None.

\section{Author Contributions}

JP prepared figure 1 and wrote the first draft of the introduction and the discussion. RK contributed significantly to the discussion. TC, ND and AH collected data from patient charts. The table was prepared from that and revised multiple times based on feedback from other authors. JD coordinated task assignments and prepared Established Facts and Novel insights. MF contributed by revising all sections of manuscripts, contributed knowledge of national-level developments and registries. The final manuscript was prepared and circulated for approval by all authors before submission.

Disclosure Statement: The authors have no conflicts of interest to declare.

NT

Corresponding Author
Jaimin Patel, MD, MSMI.
Associate Professor of Pediatrics, Neonatologist.
Assistant Chief Medical Information Officer.
Department of Pediatrics, University of Mississippi Medical
Center, Jackson, (MS,) USA
2500 N State St, W112,
Jackson, MS 39216, United States of America.
Email: ipatel@umc.edu
Phone: 601-815-7155
Cell: 708-262-3770



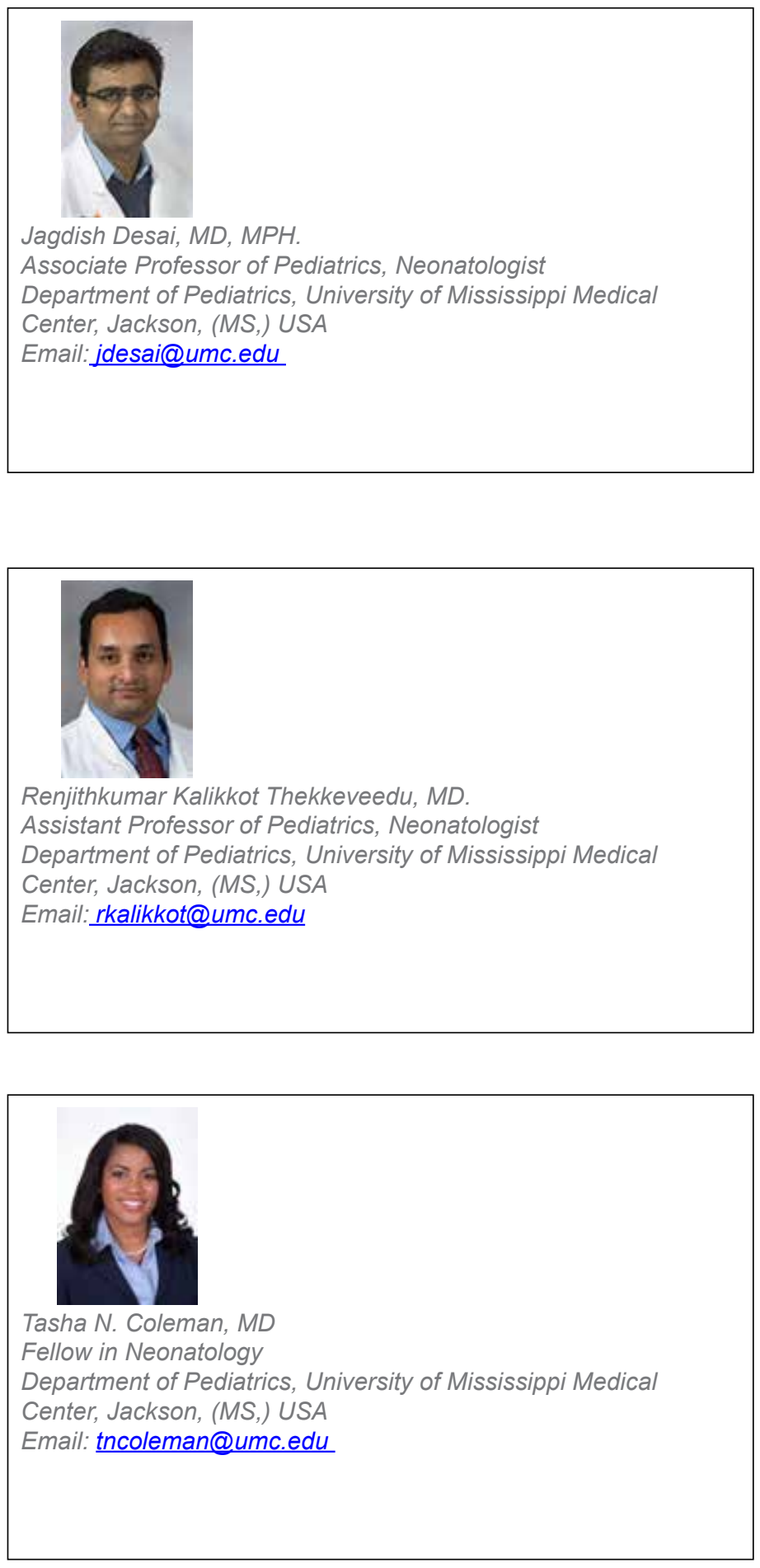
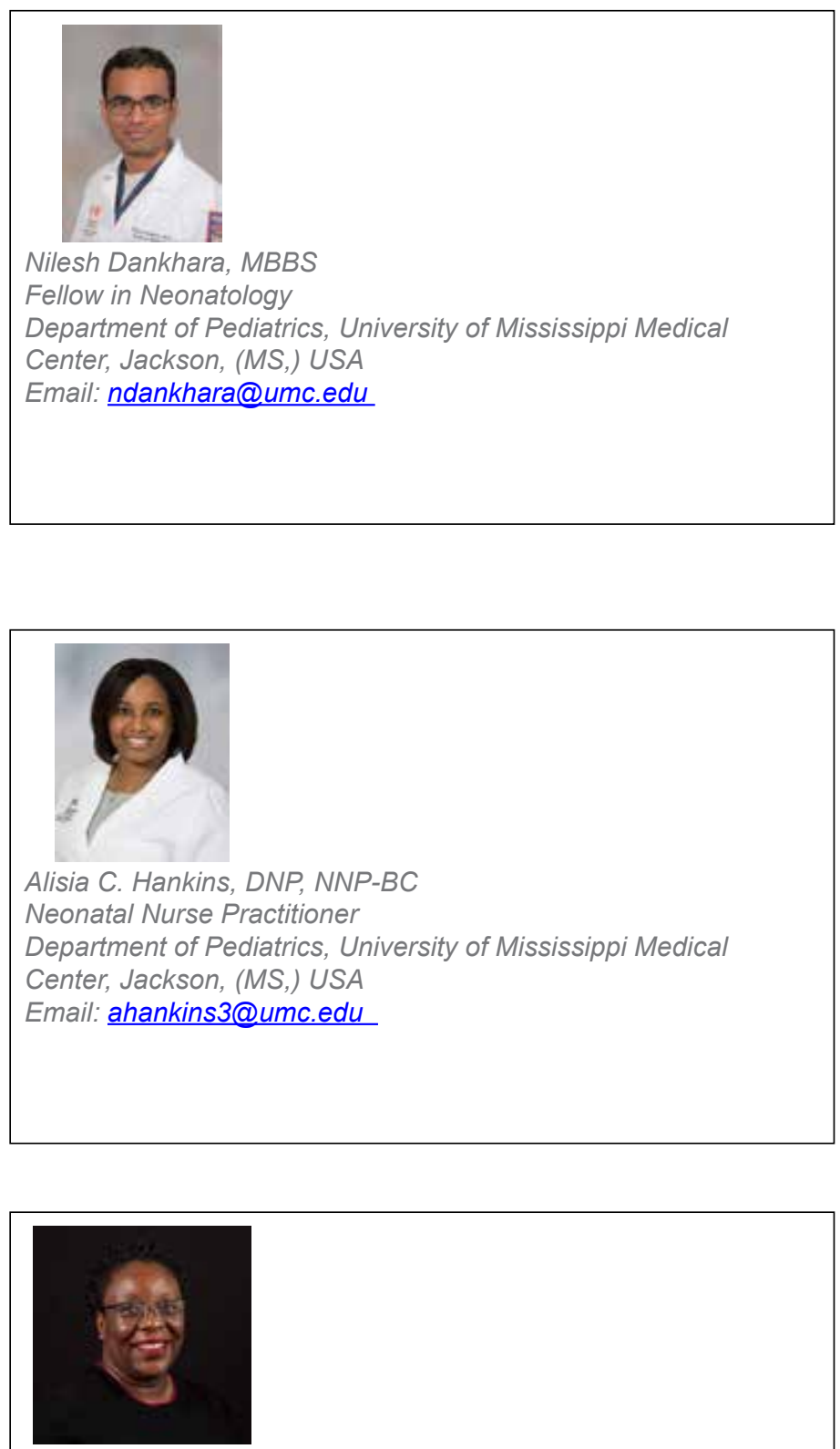

Mobolaji Famuyidea, M.D.

Professor

Chair of Neonatology

Department of Pediatrics, University of Mississippi Medical

Center, Jackson, (MS,) USA

Email: mfamuyide@umc.edu

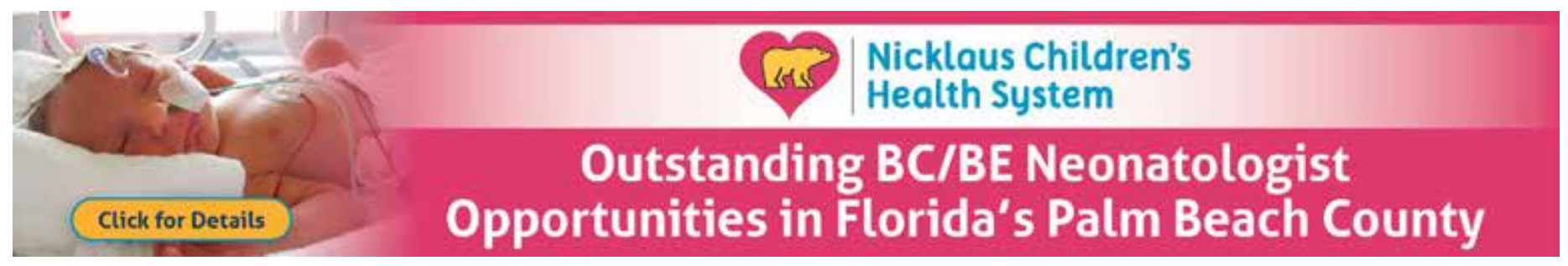

